\title{
Bromate screening as an ozonation water disinfection by-product by sequential injection spectrophotometric method
}

Raquel B. R. MESQUITA ${ }^{\dagger}$, Francisca T. S. M. FERREIRA, Ana CERQUEIRA, António O. S. S. RANGEL

Universidade Católica Portuguesa, CBQF - Centro de Biotecnologia e Química Fina Laboratório Associado, Escola Superior de Biotecnologia, Rua Diogo Botelho 1327, 4169-005 Porto, Portugal

$\dagger$ To whom correspondence should be addressed.

E-mail: $\underline{\text { rmesquita@porto.ucp.pt }}$ 


\begin{abstract}
The aim of this work was the development of an automatic sequential injection analysis method to monitor the ozonation process for water disinfection. The determination was based on the reaction between bromate and o-dianisidine in the presence of bromide in acidic medium. The determination parameters were studied and adjusted to enable bromate quantification in the range $0.35-4.0 \mathrm{mg} \mathrm{BrO}_{3}{ }^{-} / \mathrm{L}$ with a limit of detection of 20 $\mu \mathrm{g} \mathrm{BrO}_{3}{ }^{-} / \mathrm{L}$. The choice of a sequential injection procedure enabled a minimal consumption of reagents and no need for sample pre-treatment. The developed sequential injection proved to be accurate with $<5 \%$ relative deviation when compared to ICP-MS and an average of $101 \%$ in recovery percentages studies. It was effectively applied to monitor an ozonation process enabling the follow up of the process with real-time quantification of the bromate content.
\end{abstract}




\section{Introduction}

Sodium and potassium bromate are chemical compounds widely used in textile or food industries; however they do not occur naturally in water ${ }^{1}$. Bromate, specifically potassium bromate, is an antioxidant agent that only appears in water as a result of industry pollution, as a consequence of contaminated soil or when formed in some water treatment ${ }^{1}$. Furthermore, bromate has been related with adverse health effects ${ }^{2}$ and has been categorized as potentially carcinogenic to humans by the International Agency for Research on Cancer ${ }^{1}$, which is why its monitorization in waters has gain importance in the last few years.

Water safety is a major concern, so it is essential to monitor and treat it. Different methodologies have been used for water disinfection such as chlorination, membrane filtration, UV treatment, ozonation and others to effectively inactivate microorganisms present in the water ${ }^{3}$. Despite being highly effective in water disinfection, ozonation has also been associated with the production of toxic disinfection by-products namely as bromate ${ }^{3,4}$. Bromate formation is particularly problematic since it is not biodegradable in the commonly use biological filters employed after the ozonation process ${ }^{5}$. Consequently, several methods for bromate determination, mostly in water, have been reported (Table 1) such as ion chromatography ${ }^{6}$, HPLC $^{7,8}$, chemiluminescence ${ }^{9}$ and spectrophotometric methods ${ }^{10-14}$. In most those works the application range is quite similar ranging from about $1 \mu \mathrm{g} / \mathrm{L}(0.008 \mu \mathrm{M})$ to about $1 \mathrm{mg} / \mathrm{L}(8 \mu \mathrm{M})$, including a couple of flow-based

approaches $10,12,13$. Therefore, without loss of sensitivity, the flow-based approaches represent a faster, effective alternative for the bromate determination as shown with quantification rate of up to $46 \mathrm{~h}^{-1}$ reported by Tóth et al. ${ }^{10}$.

In this work, the development of a sequential injection (SI) methodology using odianisidine (ODA) for bromate spectrophotometric determination is described. The SI 
technique is known for key features namely automation, versatility, and real-time analysis and has been extensively used as a water monitoring tool ${ }^{15}$. The versatility and feasibility of SI in incorporating in-line treatments is vital in adjusting to the colour reaction specific demands ${ }^{16-18}$ and was decisive for its choice. The chosen reaction between bromate and and o-dianisidine (ODA) consists in the formation of $\mathrm{Br}_{2}$ (with bromide in excess) and consequent bromination of ODA in acid medium. The orange-brown product can be spectrophotometrically detected at $450 \mathrm{~nm}$, thus enabling the bromate quantification ${ }^{19,20}$. The developed SI technique was studied to attain the best reaction parameters and resulted in a high selective, automatic method for the real-time determination of bromate during an ozonation process (and natural waters) with no need of sample pre-treatment.

\section{Experimental}

\section{Reagents and solutions}

All solutions were prepared with analytical grade chemicals and Milli-Q water (resistivity $>18 \mathrm{M} \Omega \mathrm{cm}$, Millipore).

A potassium bromate (Merck) stock solution was daily prepared by dissolving $3 \mathrm{mg}$ of the solid in $250 \mathrm{~mL}$ water. Working standard solutions within the range $0.35-4 \mathrm{mg} / \mathrm{L}$ were prepared from the previous solution.

The reagent solution was prepared by dissolving $25 \mathrm{mg}$ of $o$-dianisidine, ODA (SigmaAldrich) and $230 \mathrm{mg}$ of potassium bromide (Merck) In $50 \mathrm{~mL}$ of $1 \mathrm{M}$ of $\mathrm{HNO}_{3}$, resulting in $2 \mathrm{mM}$ of ODA and $0.04 \mathrm{M}$ of $\mathrm{KBr}$ (a 1:20 ODA: $\mathrm{KBr}$ proportion). The reagent solution was left to stabilize overnight before use and then was stable for at least fifteen days.

The $1 \mathrm{M}$ of nitric acid solution was prepared by dilution of the commercial solution $(\mathrm{d}=$ $1.39 ; 65 \%$, Merck). 


\section{Sequential injection manifold and procedure}

The developed sequential injection (SI) method for bromate determination is depicted in Fig. 1.

The SI manifold consists of a peristaltic pump (Minipuls 3 Gilson ${ }^{\circledR}$ ) connected to the central of channel of a 10-port selection valve (Valco Cheminert ${ }^{\mathrm{TM}}$ ), where the reagent and standard/samples solutions are placed. A reaction coil with $80 \mathrm{~cm}$ length was placed in a thermostatic bath (ISCO GTR 190) at $35^{\circ} \mathrm{C}$ on the way to the detection, in a lateral port of the selection valve. An Ocean Optics HR 4000 High-Resolution charged coupled device detector (CCD), equipped with a pair of $400 \mu \mathrm{m}$ optical fibers (Ocean Optics P400-2-UV/VIS) and a Micropack DH-2000 deuterium halogen light source, was used as the detection system. A Hellma 178.011-OS flow-cell with $10 \mathrm{~mm}$ light path and $30 \mu \mathrm{L}$ inner volume was used. Data acquisition signal was obtained at $450 \mathrm{~nm}$ and it was performed through the OceanOptics - Spectrasuite software running in a personal computer (HP L1706). All the tubing connecting the different components consisted of $0.8 \mathrm{~mm}$ PTFE tube (Omnifit). The protocol sequence for the bromate determination is detailed in Table 2.

The determination of bromate was initiated by the sequential aspiration of color reagent and standard/sample plugs into the holding coil (Steps A and B). Then, the flow was reversed, promoting the mixture of the two plugs and directing them to the reaction coil immersed in the thermostatic bath at $35^{\circ} \mathrm{C}$ for a stop period of $30 \mathrm{~s}$ (Steps C and D). Finally, the formed colored product was propelled to the detector for absorbance measurement at $450 \mathrm{~nm}$ (Step E). 


\section{Sample collection and ozonation process}

Well water samples (up to about $10 \mathrm{~L}$ ) were collected (Northwestern, Portugal) and stored in the refrigerator at $4^{\circ} \mathrm{C}$ before use.

For the ozonation process, the well water sample was subdivided into three different subsamples of $2 \mathrm{~L}$ each: one was set as reference (WW1); one was spiked with $3 \mathrm{mg} / \mathrm{L}$ of potassium bromide (WW2); and one spiked with of $6 \mathrm{mg} / \mathrm{L}$ of potassium bromide (WW3). The three sub-samples were then bubbled with ozone for 1 hour using an ozone generator (Hager $\left.{ }^{\circledR}\right)$ and $100 \mathrm{~mL}$ aliquots were taken every 15 minutes for bromate quantification.

\section{Reference procedure}

The accuracy of the developed SI method was assessed by comparing the results obtained with the results acquired with an $\mathrm{iCAP}^{\mathrm{TM}} \mathrm{Q}$ Inductively coupled plasma - mass spectrometry (ICP-MS) from Thermo Fisher Scientific (Bremen, Germany).

\section{Results and Discussion}

In order to optimize the SI system and improve the sensitivity of the method, several parameters were studied, namely the colour reagent composition, the reagent and sample volumes, among others. The studies were carried out by establishing calibration curves, and choose the conditions corresponding to the highest slope.

\section{Preliminary studies - reaction kinetics}

The reaction kinetics was evaluated in a batchwise approach performed at room temperature using bromate standards within the range $0.5-3.0 \mathrm{mg} / \mathrm{L}$ and using $1 \mathrm{~mL}$ of reagent to $2 \mathrm{~mL}$ of standard/sample. 
The absorbance increase for each standard was registered for 10 min (ESI Fig.1) and it was clear that there was a significant increase up to $5 \mathrm{~min}(300 \mathrm{~s})$, in particular for the highest concentrations, then stabilizing just before $10 \mathrm{~min}$. So, calibration curves were established with the registered values at 60, 120, 180, 240 and $300 \mathrm{~s}$ (ESI Fig.2). The sensitivity, calibration curve slope, increased with increasing reaction time, but the increase became less significant, $<10 \%$, from $240 \mathrm{~s}$ to $300 \mathrm{~s}$ (about $7 \%$ increase).

\section{Reaction kinetics - sequential injection protocol}

The first study in flow approach was to implement a stoppage time in the sequential injection protocol.

The same volume proportion of 1 reagent: 2 standard was used: $180 \mu \mathrm{L}$ reagent and 360 $\mu \mathrm{L}$ of standard. Stop periods, set to be at the detector, were tested ranging from 0 (no stop period) to $30 \mathrm{~s}$ (ESI Fig.3).

The sensitivity increased with the increase of the stoppage time; with a $10 \mathrm{~s}$ stop period the sensitivity was over $50 \%$ higher than without stop period. That increase was smaller for higher stoppage periods (i.e. from 10 to $15 \mathrm{~s}$ increased only about $20 \%$ and from 25 to $30 \mathrm{~s}$ below $10 \%$ ). Nevertheless, the stoppage period of $30 \mathrm{~s}$ was set and used in the following studies.

In parallel, the impact of the flow rate was also evaluated for the propelling steps, as these are the ones relating to the reaction mixture and kinetics. The aspiration of reagents was set to a $60 \mu \mathrm{L} / \mathrm{s}$ flow rate to minimize dispersion and enable a faster cycle. However for the propelling steps, before the stop period, having a lower flow rate, $40 \mu \mathrm{L} / \mathrm{s}$, resulted in a better mixture (increase about 5\% the slope) and lower refraction index, respectively. 


\section{Sample/Standard volume study}

With the stop period set to $30 \mathrm{~s}$, the influence of the sample volume on the calibration curve parameters was tested and volumes of $300,360,420,480$ and $540 \mu \mathrm{L}$ were studied (Fig. 2 A). The sensitivity increased up to $360 \mu \mathrm{L}$ (highest slope was obtained) and then kept quite stable so $360 \mu \mathrm{L}$ was the chosen volume.

\section{Study of color reagent volume and composition}

Then, having established the sample/standard volume, the color reagent volume and composition were studied. The volume of $300 \mu \mathrm{L}$ was chosen from the tested volumes of 120, 180, 240, 300 and $360 \mu \mathrm{L}$ (Fig.2 B). The sensitivity increased with the increase of the reagent volume but, although there was a significant increase up to $300 \mu \mathrm{L}(>20 \%)$, it became negligible from 300 to $360 \mu \mathrm{L}(<10 \%)$. Therefore, in order to avoid the unnecessary reagent consumption, the volume chosen was $300 \mu \mathrm{L}$.

Three reagent proportions of o-dianisidine (ODA) and potassium bromide (ODA : KBr) were studied: 1:50, 1:20 (proportion initially used), 1:10 and 1:5 (Fig. 3 A). For the 1:5 proportion, there was no correlation between the absorbance signal and the bromate standards. The highest sensitivity was obtained with the 1:20 proportion so it was the chosen proportion.

\section{Reaction temperature}

The ODA bromate reaction is temperature dependent ${ }^{19,20}$. Therefore, three temperatures were studied, namely $25^{\circ} \mathrm{C}$ (room temperature, RT), $35^{\circ} \mathrm{C}, 45^{\circ} \mathrm{C}$ and $55^{\circ} \mathrm{C}$ (Fig. 3B). At $55{ }^{\circ} \mathrm{C}$, the in-line bubble formation interfered with the signal reading, making it impossible to distinguish from air bubbles caused signals, and so this temperature was discarded. 
As expected, the sensitivity (calibration curve slope) increase with the temperature increase. As the increase was higher from the RT to $35{ }^{\circ} \mathrm{C}(11 \%)$ then from $35{ }^{\circ} \mathrm{C}$ to 45 ${ }^{\circ} \mathrm{C}(<6 \%)$ and considering the problem of bubbles formation, the chosen temperature was $35^{\circ} \mathrm{C}$

\section{Interferences studies}

The potential interference of some anions $\left(\mathrm{SiO}_{3}{ }^{-} \cdot \mathrm{NO}_{2}{ }^{-} \cdot \mathrm{NO}_{3}{ }^{-}\right.$and $\left.\mathrm{Cl}^{-}\right)$was assessed by calculating the interference percentage (IP). To calculate the IP, mixed standards with bromate $(2.0 \mathrm{mg} / \mathrm{L})$ and different concentrations of the potential interference ion were prepared (Table 3 ). The absorbance signal of the mixed standard $\left(A_{\text {Anion }}\right)$ and the absorbance signal of the bromate standard $\left(\mathrm{ArrO}_{3}^{-}\right)$were used in the Eq. (1).

$I P(\%)=\left[\frac{\left(A_{\text {Anion }^{-}}-A_{\mathrm{BrO}_{3}}{ }^{-}\right)}{A_{\mathrm{BrO}_{3}}{ }^{-}}\right] \times 100$

The tested concentrations for each tested anion correspond to suggested values and maximum admissible concentration in natural waters ${ }^{1}$. It was considered that to be no interference when the calculated IP $<10 \%$. Therefore, there were no significant interferences from the tested anions.

\section{Analytical features of the developed method}

Having finished the studies for optimization of the developed SI method for bromate determination, the main features are summarized in Table 4.

The limit of detection (LOD) and the limit of quantification (LOQ) were calculated according to IUPAC recommendation ${ }^{21,22}$ as the concentration corresponding to three and ten times, respectively, the standard deviation of ten consecutive blank signals. The 
concentrations were calculated by interpolating, in the calibration curve, the blank signal average plus three (LOD) or ten (LOQ) times the standard deviation of ten blank signals. This mathematical calculation resulted in a significant difference between the LOD and LOQ and some samples were analysed between those values.

The determination rate was calculated based on the time per cycle, which according to the described protocol (shown in Table 2) plus the equipment's response, takes 95 seconds. The consumptions values were calculated per determination, corresponding to one full cycle. The inter day and intraday repeatability of the developed SI was assessed by calculating relative standard deviation (RSD) of calibration curve slopes.

For the intraday repeatability, a RSD $=1 \%$ was obtained from four calibration curves; for the inter day repeatability, a $\mathrm{RSD}=9 \%$ was obtained from five calibration curves established over a 15-days period.

\section{Method validation - Accuracy assessment}

To evaluate the accuracy of the developed SI method three well water samples were analysed (WS1, WS2, WS3) and the values obtained compared to the reference procedure ICP-MS. All samples were analysed in triplicate. WS1 was spiked with bromide (about $1.5 \mathrm{mg} / \mathrm{L}$ ) and ozonized for $30 \mathrm{~min}$; WS2 was not ozonized and no bromide addition was made; to WS3, no bromide was added but it was ozonized for $30 \mathrm{~min}$. As expected, the bromate concentration values for WS2 and WS3 were quite low, below the calculated LOQ; however, as the values were above LOD, and quite similar to those of the ICP-MS analysis, the results are presented anyway.

The calculated RD between the two sets of results were: $\mathrm{RD}_{\mathrm{WS} 1}=3 \%(1.48 \pm 0.02 \mathrm{mg} / \mathrm{L}$ $\mathrm{BrO}_{4}^{-}$by ICP-MS and $1.53 \pm 0.01 \mathrm{mg} / \mathrm{L}$ with the developed SI method); $\mathrm{RD}_{\mathrm{WS} 2}=1 \%$ $\left(0.051 \pm 0.001 \mathrm{mg} / \mathrm{L} \mathrm{BrO}_{4}{ }^{-}\right.$by ICP-MS and $0.052 \pm 0.014 \mathrm{mg} / \mathrm{L}$ with the developed SI 
method $) ; \mathrm{RD}_{\mathrm{WS} 3}=-6 \%\left(0.033 \pm 0.001 \mathrm{mg} / \mathrm{L} \mathrm{BrO}_{4}{ }^{-}\right.$by ICP-MS and $0.031 \pm 0.005 \mathrm{mg} / \mathrm{L}$ with the developed SI method).

The WS1 sample was also analysed prior to the ozonation process and, as expected, the values did not match as the ICP-MS accounts for total bromine, and the developed SI method accounts for bromate.

To further establish accuracy, recovery percentages were calculated according to IUPAC recommendations ${ }^{23}$ using both natural and ozonised water (Table 5).

Well waters samples were spiked with bromate using 100 and/or $300 \mu \mathrm{L}$ of a $160 \mathrm{mg}$ $\mathrm{BrO}_{3}{ }^{-} / \mathrm{L}$ stock solution to a final volume of $20 \mathrm{and} /$ or $50 \mathrm{~mL}$ of well water (W). Then, samples were analysed with the developed SI method and the recovery percentage calculated (Table 5) according to the Eq. (2).

$\% R=\left(\left[\mathrm{BrO}_{3}^{-}\right]_{\text {found }}-\left[\mathrm{BrO}_{3}^{-}\right]_{\text {initial }}\right) \div\left[\mathrm{BrO}_{3}^{-}\right]_{\text {added }}$

To validate the full range of the calibration curve, some of the well water samples used were previously ozonized (OW) which explains the high initial values observed. The average percentage for recovery tests was $101 \%$ with a standard deviation of $11 \%$ and the calculated $\mathrm{T}$ value was 0.417 for a critical $\mathrm{T}$ value 2.423 , indicating that there was no evidence of matrix multiplicative interferences.

\section{Method application - Application to the ozonation process}

The developed SI method was applied to the entire ozonation process of three well waters (WW1, WW2, WW3), as described in section 2.3., by analysing the aliquots collected every 15 min up to one hour (Fig. 4).

The well waters had different initial content of bromide, resulting in significant differences in the formed bromate. Even with short ozonation time (15 min) the bromate 
formation corresponds to $1 / 4$ of the initial bromide content. Therefore, a natural water with more than $40 \mu \mathrm{g} / \mathrm{L}$ of bromide cannot undergo ozonation process for more than $15 \mathrm{~min}$ in order to comply with the legal limit of $10 \mu \mathrm{g} / \mathrm{L}$ of bromate.

In both WW\#2 and WW\#3 (with high content of bromide), when the concentration of formed bromate was above $2.0 \mathrm{mg} / \mathrm{L}$, apparently a parallel reaction between bromide and bromate occurred and caused bromate concentration to decrease, probably due to the production of bromine $\left(\mathrm{Br}_{2}\right)$. This parallel reaction causes the bromate concentration to decrease and when it becomes below $2.0 \mathrm{mg} / \mathrm{L}$ apparently the parallel reaction stops causing the bromate concentration to increase again.

\section{Conclusions}

The proposed SI method for bromate determination is highly effective to monitor water ozonation process. Being the maximum acceptable concentration of bromate in drinking waters of $10 \mu \mathrm{g} / \mathrm{L}$, identical to the developed SI LOD, it is a useful tool to ensure that the regulations enforcement. Although there is no significant improvement in the attained LOD when compared to other flow procedures in Table 1 the quantification range is wider enabling to perform an effective monitoring of ozonation processes. The developed methodology proved to be fast and reliable with a high determination rate (37 determination $/ \mathrm{h}$ ) and a good repeatability (interday $\mathrm{RSD}=9 \%$ ). These features could be essential in a potential in-line application to the water ozonation process. 


\section{Acknowledgements}

This work was supported by National Funds from FCT - Fundação para a Ciência e a Tecnologia through project UIDB/50016/2020.

\section{References}

1. WHO. World Health Organization, WHO Chron., 2008, 688.

2. Y. Kurokawa, A. Maekawa, M. Takahashi, and Y. Hayashi, Environ. Health Perspect., 1990, 87, 309.

3. J. Xi, F. Zhang, Y. Lu, and H.-Y. Hu, Sep. Purif. Technol., 2017, 179, 45.

4. M. Tammaro, V. Fiandra, A. Salluzzo, A. Patti, and A. Lancia, J. Environ. Chem. Eng., 2016, 4, 3293.

5. I. H. Aljundi, Desalination, 2011, 277, 24.

6. M. Achilli and L. Romele, J. Chromatogr. A, 1999, 847, 271.

7. J. Gao, W. Yang, J. Kang, J. Hou, and H. Bian, J. Chromatogr. A, 1997, 789, 195.

8. K. Himata, M. Noda, S. Ando, and Y. Yamada, Food Addit. Contam., 1997, 14, 809.

9. J. C. G. Esteves da Silva, J. R. M. Dias, and J. M. C. S. Magalhães, Anal. Chim. Acta, 2001, 450, 175.

10. I. V. Tóth, I. C. Santos, C. F. M. Azevedo, J. F. S. Fernandes, A. O. S. S. Rangel, R. N. M. J. Páscoa, and R. B. R. Mesquita, Anal. Sci., 2013, 29, 563.

11. S. Farrell, J. F. Joa, and G. E. Pacey, Anal. Chim. Acta, 1995, 313, 121.

12. M. J. Almendral-Parra, A. Alonso-Mateos, and M. S. Fuentes-Prieto, J. Fluoresc., 2008, $18,1169$.

13. S. M. Oliveira, M. A. Segundo, A. O. S. S. Rangel, J. L. F. C. Lima, and V. Cerdà, Anal. Lett., 2011, 44, 284. 
14. L. Romele and M. Achilli, Analyst, 1998, 123, 291.

15. R. B. R. Mesquita and A. O. S. S. Rangel, Anal. Chim. Acta, 2009, 648, 7.

16. M. A. Segundo and A. O. S. S. Rangel, J. Flow Inject. Anal., 2002, 19, 3.

17. A. Economou, P. D. Tzanavaras, and D. G. Themelis, J. Chem. Educ., 2005, 82, 1820.

18. N. W. Barnett, C. E. Lenehan, and S. W. Lewis, TrAC - Trends Anal. Chem., 1999, $18,346$.

19. A. Alonso-Mateos, M. J. Almendral-Parra, and M. S. Fuentes-Prieto, Talanta, 2008, $76,892$.

20. M. J. Almendral, A. Alonso, and M. S. Fuentes, J. Environ. Monit., 2009, 11, 1381.

21. I. International Union of Pure and Applied Chemistry, Pure Appl. Chem., 1976, 45, 99.

22. L. A. Currie, Int. Union Pure Appl. Chem., 1995, 67, 1699.

23. D. T. Burns, K. Danzer, and A. Townshend, Pure Appl. Chem., 2002, 74, 2201. 
Table 1 Summary of the some reported methods for bromate determination in water samples; LOD, limit of detection; FS, flow system; FI, flow injection; MSFIA, multi syringe flow injection analysis.

\begin{tabular}{|c|c|c|c|c|c|}
\hline Target sample & $\begin{array}{l}\text { Method of detection/ } \\
\text { determination }\end{array}$ & Dynamic range & LOD & $\begin{array}{l}\text { Quantification } \\
\text { rate }\end{array}$ & Reference \\
\hline $\begin{array}{l}\text { Water } \\
\text { (disinfection process) }\end{array}$ & Spectrophotometric / SI & $0.30-4.0 \mathrm{mg} / \mathrm{L}$ & $10 \mu \mathrm{g} / \mathrm{L}$ & $37 \mathrm{~h}^{-1}$ & This Work \\
\hline Drinking water & Chromatography & $2-50 \mu \mathrm{g} / \mathrm{L}$ & $0.1 \mu \mathrm{g} / \mathrm{L}$ & n.r. & 6 \\
\hline Water & Chemiluminescent / FS & $\begin{array}{l}0.36-500 \mu \mathrm{M} \\
(0.046-64 \mathrm{mg} / \mathrm{L})\end{array}$ & $\begin{array}{l}0.08 \mu \mathrm{M} \\
(10 \mu \mathrm{g} / \mathrm{L})\end{array}$ & n.r. & 9 \\
\hline Bottled water & Spectrophotometric / FI & $1-20 \mu \mathrm{g} / \mathrm{L}$ & $0.2 \mu \mathrm{g} / \mathrm{L}$ & $46 \mathrm{~h}^{-1}$ & 10 \\
\hline Water & Spectrophotometry & $1-799 \mu \mathrm{g} / \mathrm{L}$ & $0.67 \mu \mathrm{g} / \mathrm{L}$ & n.r. & 11 \\
\hline Ozonized water & Fluorimetric / FI & $4-200 \mu \mathrm{g} / \mathrm{L}$ & $0.9 \mu \mathrm{g} / \mathrm{L}$ & $10 \mathrm{~h}^{-1}$ & 12 \\
\hline Water & $\begin{array}{l}\text { Spectrophotometric } \\
\text { MSFIA }\end{array}$ & $25-750 \mu \mathrm{g} / \mathrm{L}$ & $6 \mu \mathrm{g} / \mathrm{L}$ & $35 \mathrm{~h}^{-1}$ & 13 \\
\hline Drinking water & Spectrophotometry & $0-20 \mu \mathrm{g} / \mathrm{L}$ & $1 \mu \mathrm{g} / \mathrm{L}$ & n.r. & 14 \\
\hline
\end{tabular}

n.r. - not reported 
Table 2 Sequence protocol of the developed SI method for bromate determination in waters

\begin{tabular}{cccccl}
\hline Step & Port & Time (s) & Flow Rate $(\mu \mathbf{L} / \mathbf{s})$ & Volume $(\boldsymbol{\mu L})$ & Description \\
\hline A & 1 & 5 & 60 & 300 & Aspiration of the colour reagent \\
\hline B & $2-8$ & 6 & 60 & 360 & Aspiration of sample/standard \\
\hline C & 9 & 15 & 40 & 600 & Propelling the mixture to the \\
& & & & & thermostatic bath reaction coil \\
D & 9 & 30 & 0 & - & Stop period \\
\hline E & 9 & 38 & 40 & 1520 & Propelling to detector for absorbance \\
& & & & & measurement and signal registration \\
\hline
\end{tabular}


Table 3 Assessment of potential interferences of other anions studied by calculation of the interference percentage in the absorbance signal.

\begin{tabular}{lcc}
\hline Potential interfering anion & Tested concentration & Interference percentage (IP) \\
\hline $\mathrm{SiO}_{3}{ }^{-}$ & $15 \mathrm{mg} / \mathrm{L}$ & $5 \%$ \\
$\mathrm{NO}_{2}^{-}$ & $1.0 \mathrm{mg} / \mathrm{L}$ & $2 \%$ \\
$\mathrm{NO}_{3}^{-}$ & $50 \mathrm{mg} / \mathrm{L}$ & $3 \%$ \\
$\mathrm{Cl}^{-}$ & $1.0 \mathrm{~g} / \mathrm{L}$ & $3 \%$ \\
\hline
\end{tabular}


Table 4 Features of the developed method for bromate determination

\begin{tabular}{|c|c|}
\hline Dynamic range (mg/L) & $0.35-4.0$ \\
\hline Calibration curve $^{1}$; & $\mathrm{A}=(0.102 \pm 0.003)\left[\mathrm{BrO}_{3}^{-}\right]+(0.124 \pm 0.015)$ \\
\hline $\mathrm{A}=\mathrm{S} \times\left[\mathrm{BrO}_{3}^{-}\right] \mathrm{mg} / \mathrm{L}+\mathbf{b}$ & $\mathrm{R}^{2}=0.9992 \pm 0.0002$ \\
\hline $\operatorname{LOD}(\mu \mathrm{g} / \mathrm{L})$ & 20 \\
\hline $\operatorname{LOQ}(\mu \mathrm{g} / \mathrm{L})$ & 312 \\
\hline Determination rate $\left(h^{-1}\right)$ & 37 \\
\hline Effluent volume (mL) & 2.7 \\
\hline
\end{tabular}

Consumption per determination $\quad$ ODA $150 \mu \mathrm{g} ; \mathrm{KBr} 1.7 \mathrm{mg} ; \mathrm{HNO}_{3} 19 \mathrm{mg}$

${ }^{1} n=4$ 
Table 5 Recovery percentages for accuracy validation using well water (W) and ozonized well (OW) water with prior addition of bromate; SD, standard deviation; LOD, limit of detection.

\begin{tabular}{|c|c|c|c|c|c|c|c|}
\hline \multirow{2}{*}{ Water source } & \multirow{2}{*}{ Sample ID } & \multicolumn{2}{|l|}{ Initial } & \multirow{2}{*}{$\begin{array}{l}\text { Added } \\
\mathrm{mg} \mathrm{BrO}_{3}^{-} / \mathrm{L}\end{array}$} & \multicolumn{2}{|l|}{ Founded } & \multirow{2}{*}{ Recovery, \% } \\
\hline & & $\mathrm{mg} \mathrm{BrO}_{3}^{-} / \mathrm{L}$ & SD & & $\mathrm{mg} \mathrm{BrO}_{3}^{-}$ & SD & \\
\hline \multirow{7}{*}{ well water } & \multirow{2}{*}{ W\#1 } & \multirow{2}{*}{$<\mathrm{LOD}$} & & 0.774 & 0.763 & 0.032 & $99 \%$ \\
\hline & & & & 2.321 & 2.554 & 0.05 & $110 \%$ \\
\hline & $\mathrm{W} \# 2$ & $<\mathrm{LOD}$ & & 0.325 & 0.335 & 0.056 & $103 \%$ \\
\hline & W\#3 & $<\mathrm{LOD}$ & & 0.325 & 0.298 & 0.092 & $92 \%$ \\
\hline & W\#4 & $<\mathrm{LOD}$ & & 0.325 & 0.306 & 0.016 & $94 \%$ \\
\hline & $\mathrm{W} \# 5$ & $<\mathrm{LOD}$ & & 0.325 & 0.328 & 0.077 & $101 \%$ \\
\hline & $\mathrm{W} \# 6$ & $<\mathrm{LOD}$ & & 0.325 & 0.278 & 0.023 & $86 \%$ \\
\hline \multirow{14}{*}{ ozonized well } & \multirow{2}{*}{$O W \# 1$} & \multirow{2}{*}{0.231} & \multirow{2}{*}{0.001} & 0.797 & 1.127 & 0.057 & $112 \%$ \\
\hline & & & & 2.390 & 2.912 & 0.028 & $112 \%$ \\
\hline & \multirow{2}{*}{ OW\#2 } & \multirow{2}{*}{0.482} & \multirow{2}{*}{0.007} & 0.797 & 1.368 & 0.027 & $111 \%$ \\
\hline & & & & 2.390 & 2.623 & 0.062 & $90 \%$ \\
\hline & \multirow{2}{*}{$O W \# 3$} & \multirow{2}{*}{0.178} & \multirow{2}{*}{0.031} & 0.797 & 0.935 & 0.022 & $95 \%$ \\
\hline & & & & 2.390 & 2.466 & 0.073 & $96 \%$ \\
\hline & \multirow{2}{*}{ OW\#4 } & \multirow{2}{*}{2.45} & \multirow{2}{*}{0.05} & 0.797 & 3.334 & 0.036 & $111 \%$ \\
\hline & & & & 2.390 & 5.115 & 0.029 & $111 \%$ \\
\hline & \multirow{2}{*}{ OW\#5 } & \multirow{2}{*}{3.83} & \multirow{2}{*}{0.01} & 0.797 & 4.728 & 0.022 & $113 \%$ \\
\hline & & & & 2.390 & 6.275 & 0.037 & $102 \%$ \\
\hline & \multirow{2}{*}{ OW\#6 } & \multirow{2}{*}{4.94} & \multirow{2}{*}{0.07} & 0.797 & 5.630 & 0.027 & $87 \%$ \\
\hline & & & & 2.390 & 7.211 & 0.066 & $95 \%$ \\
\hline & OW\#7 & 3.03 & 0.02 & 0.797 & 3.778 & 0.038 & $94 \%$ \\
\hline & OW\#8 & 1.26 & 0.03 & 2.390 & 3.819 & 0.029 & $107 \%$ \\
\hline
\end{tabular}

Note: the values in italic are below LOQ but above LOD 


\section{Figure Captions}

Fig. 1 Manifold of the developed SI methodology for the bromate determination in natural waters: $\mathrm{P}$, peristaltic pump; $\mathrm{HC}$, holding coil with $3 \mathrm{~m}$; SV, selection valve (\# 10 ports); S1-S6, Standard/sample solutions; W, waste; $\mathrm{R}_{1}$, reaction coil with $80 \mathrm{~cm}$; $\mathrm{T}$, thermostatic bath at $35^{\circ} \mathrm{C} ; \lambda$, spectrophotometer detector at $450 \mathrm{~nm}$.

Fig. 2 Study of the sample (A) and reagent (B) volumes upon the calibration curve slope (०) and intercept ( $\square)$; the points in full correspond to the slope and intercept values of the chosen volumes; the error bars represent $5 \%$ error.

Fig. 3 Study of the effect of reagent composition (A) and reaction temperature (B) upon the calibration curve slope; the darker bars represent the chosen conditions; the error bars represent $5 \%$ error.

Fig. 4 Monitoring the ozonation process of three well water (WW) samples: with no addition of bromide (WW \#1), with addition of $3 \mathrm{mg} \mathrm{KBr} / \mathrm{L}$ (WW \#2), and with addition of $6 \mathrm{mg} \mathrm{KBr} / \mathrm{L}$; the error bars represent the standard deviation. 
Figure 1

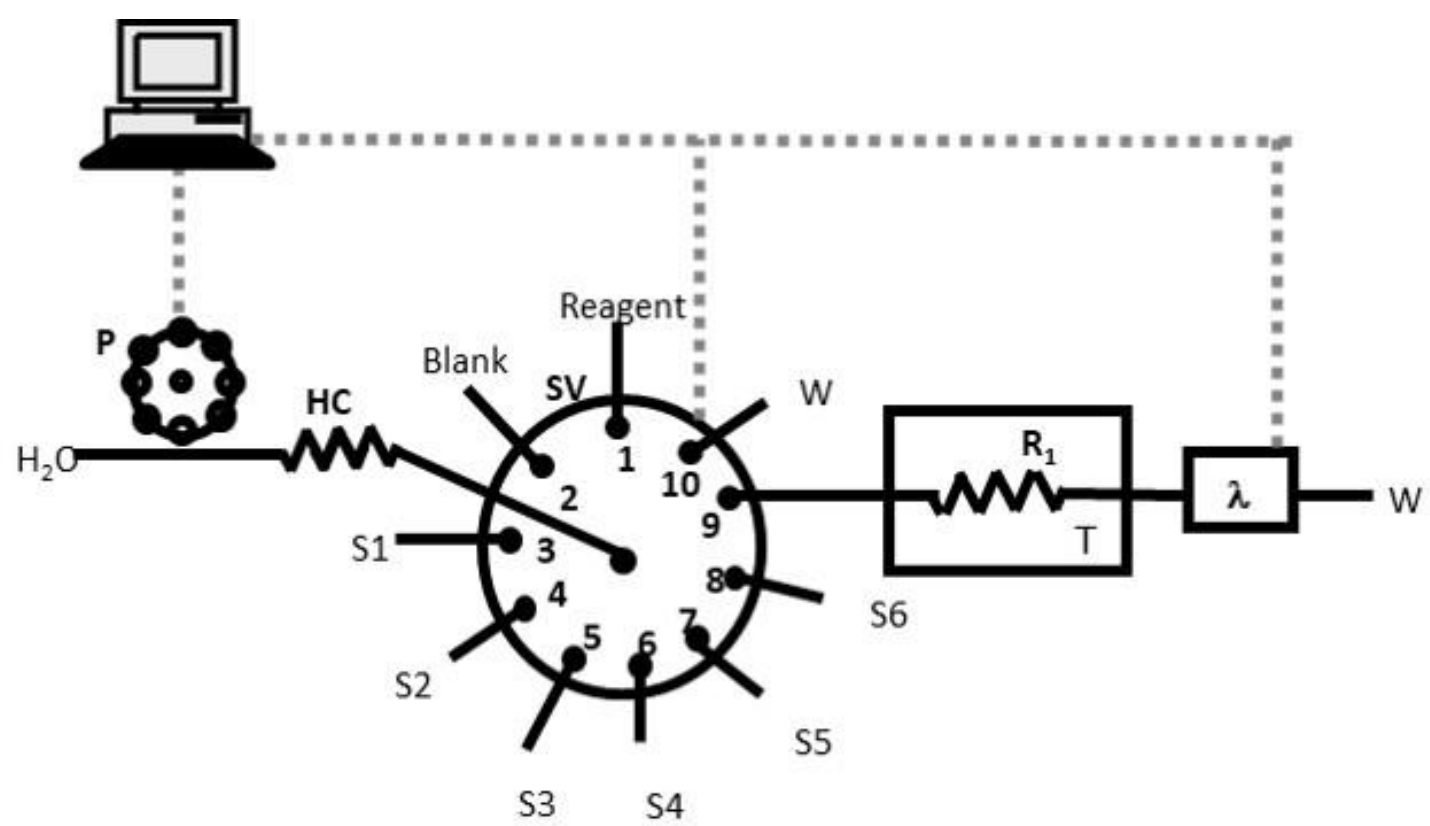


Figure 2

A

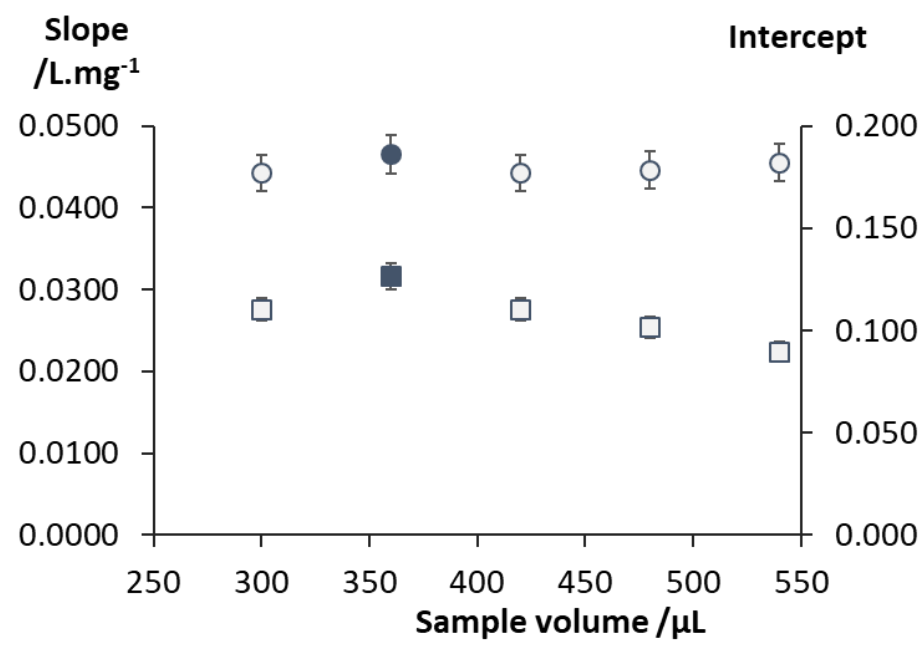

B

$$
\begin{gathered}
\text { Slope } \\
\text { /L.mg } \\
\text { - }
\end{gathered}
$$

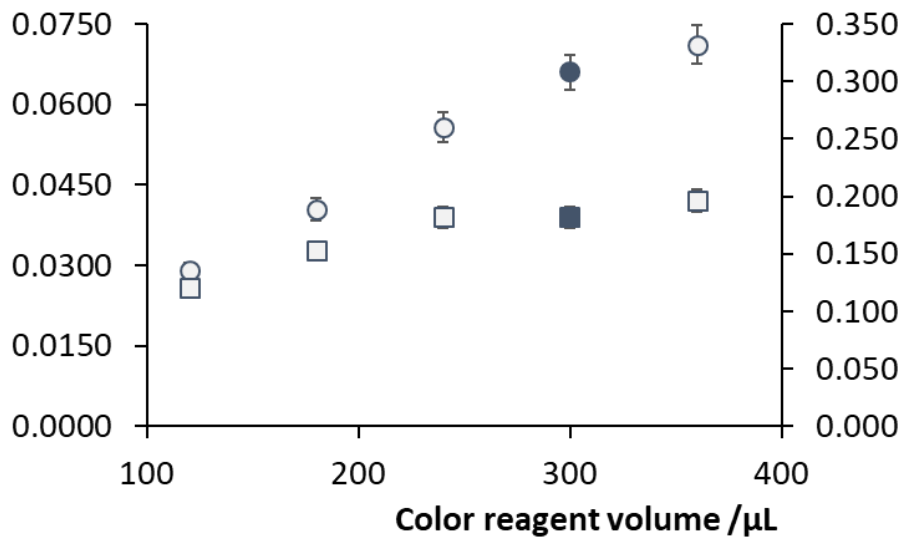


Figure 3

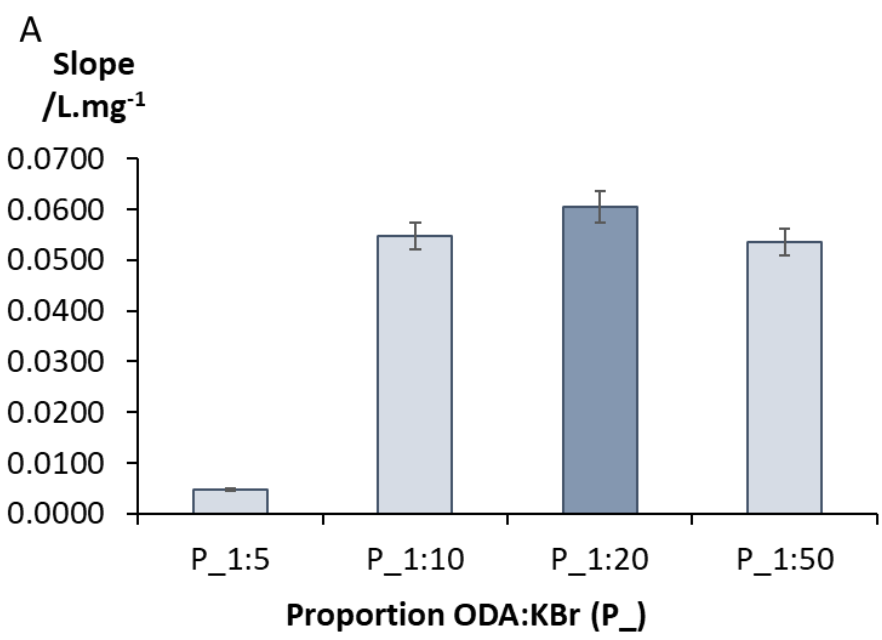

B

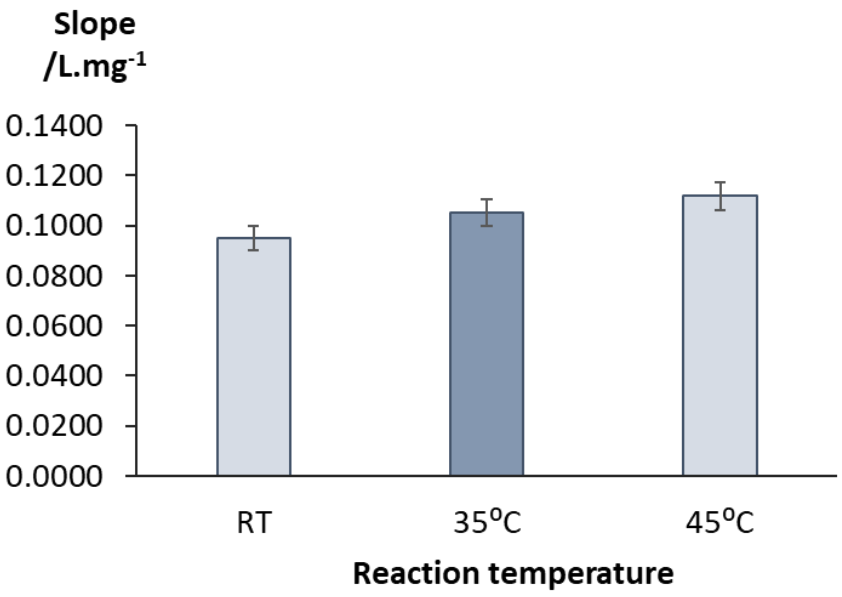


Figure 4

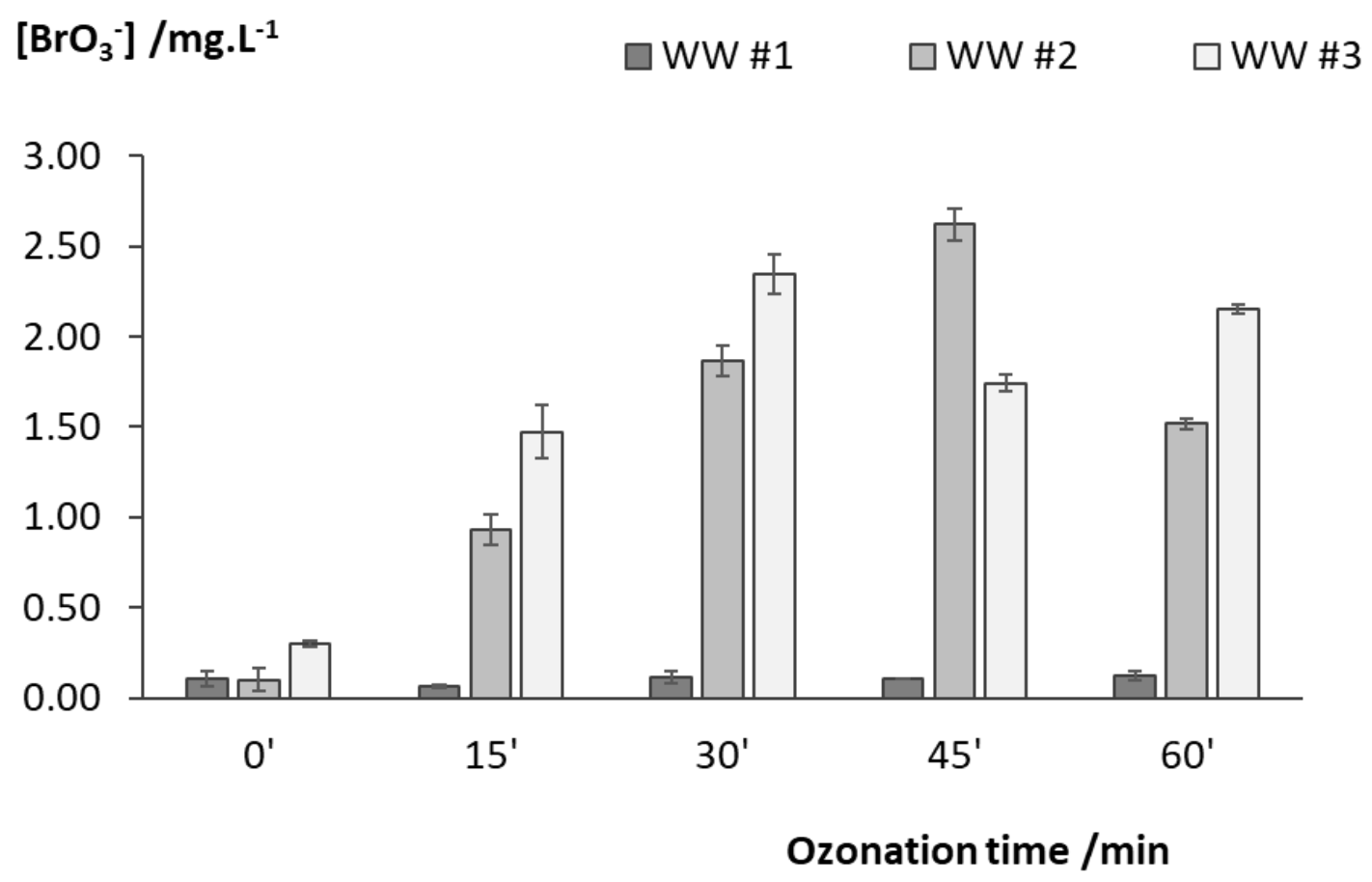

